\title{
ICONOS, DE RAFAEL ALMANZA ALONSO: UN NUEVO CASO DE USO INTENCIONAL DEL ENDECASÍLABO DACTÍLICO
}

\author{
RAFAEL ALMANZA ALONSO'S ICONOS: \\ A NEW CASE IN THE INTENTIONAL USE \\ OF THE DACTYLIC HENDECASYLLABLE
}

\author{
Carlos Manresa González \\ Universidad de Montreal
}

Resumen: El endecasílabo anapéstico, dactílico o de gaita gallega ha sido utilizado en pocas ocasiones en la poesía española. El siguiente trabajo describe la existencia de un nuevo caso de endecasílabo anapéstico, dactílico o de gaita galleta en la obra del poeta cubano contemporáneo Rafael Almanza Alonso. Primero, se hace un recorrido por su poesía de juventud para demostrar su marcado interés por el empleo de este metro. Se estudia en particular el uso intencional o uniforme de la variedad dactílica del endecasílabo en el himno Iconos de este autor. Al comparar este himno con los textos poéticos hasta ahora documentados por la crítica que han usado esta variante del endecasílabo, se pretende demostrar que Iconos constituye el ejemplo de uso uniforme más extenso de este endecasílabo en la poesía lírica española. Por último, para su estudio, se sugiere utilizar el concepto teórico de verso variable de Oldřich Bělič. 
Palabras clave: Endecasílabo dactílico, Rafael Almanza Alonso, verso variable.

Abstract: The dactylic hendecasyllable has been rarely used in Spanish poetry. The following paper describes the existence of a new case of the dactylic hendecasyllable in the work of contemporary Cuban poet Rafael Almanza Alonso. We will first study his youth poetry in order to demonstrate their strong interest in the use of the hendecasyllable. We will also document the intentional use of the dactylic hendecasyllable by this author in the hymn Iconos. By comparing this poem with the poetic texts that have used this variant of hendecasyllable, so far documented by critics, we aim to demonstrate that Iconos is the example of the largest and uniform use of this variety of hendecasyllable in the lyric Spanish poetry. Finally, we suggest to study this hendecasyllable by using the metric theoretic concept variable verse from Oldřich Bělič.

Keywords: Dactylic hendecasyllable, Rafael Almanza Alonso, variable verse. 

tar un nuevo caso de uso uniforme de endecasílabo dactílico, estudiar la métrica del poema Iconos, del poeta cubano Rafael Almanza Alonso, y explicar el empleo particular que hace de este metro ${ }^{1}$.

En español, el verso de once sílabas con acentos internos en las sílabas $4^{\mathrm{a}}$ y $7^{\mathrm{a}}$, además del acento final en $10^{\mathrm{a}}$ sílaba, y eventualmente en la $1^{\mathrm{a}}$ o la $2^{\mathrm{a}}$ sílabas, es denominado anapéstico por Milá y Fontanals ${ }^{2}$, dactílico por Bello ${ }^{3}$ y Navarro Tomás ${ }^{4}$ (1968), $B_{2}$ y $B_{3}$ por Henríquez Ureña ${ }^{5}, \mathrm{~B}_{3}$ o gallego-portugués por Baehr ${ }^{6}$ $\mathrm{y}$ de gaita gallega por Domínguez Caparrós ${ }^{7}$. Aunque nuestra intención es introducir la terminología del verso variable de Bělič para aplicarla, en este caso, a este tipo de verso silabotónico, preferimos, por el momento y en aras de no incrementar la ya variada diversidad de clasificaciones, limitarnos a denominar este endecasílabo como endecasílabo dactílico.

Los principales estudiosos de la métrica que hacen referencia a este tipo de endecasílabo son Andrés Bello ${ }^{8}$, Manuel Milá

${ }^{1}$ Este artículo es una versión abreviada de un capítulo de la tesis de grado del autor.

2 Milá y Fontanals, Manuel: «Del decasílabo y el endecasílabo anapésticos», en Obras completas del Doctor D. Manuel Milá y Fontanals. Opúsculos literarios, segunda serie. Tomo V. Barcelona: Librería de Álvaro Verdaguer, 1893.

3 Bello, Andrés: Obras completas. Estudios filológicos I. Tomo VI. Caracas: Fundación La Casa Bello, 1981. 2a edición.

4 Navarro Tomás, Tomás: Métrica española. Reseña histórica y descriptiva. La Habana: Edición Revolucionaria, Instituto del Libro, 1968.

5 Henríquez Ureña, Pedro: Obras completas. Estudios Métricos. Tomo III. Santo Domingo: Secretaría de Estado de Cultura, Editora Nacional, 2003.

6 BAEHr, Rudolf: Manual de versificación española. Madrid: Gredos, 1989. $4^{\mathrm{a}}$ reimpresión.

7 Domínguez Caparrós, José: Diccionario de métrica española. Madrid: Alianza Editorial, 2007. 2 ${ }^{\mathrm{a}}$ reimpresión.

${ }^{8}$ BeLlo, Andrés: Obras completas, cit. 
y Fontanals 9 , Eduardo de la Barra ${ }^{10}$, Julio Vicuña Cifuentes ${ }^{11}$, Pedro Henríquez Ureña ${ }^{12}$ y Tomás Navarro Tomás ${ }^{13}$. El uso intencional, uniforme o independiente del moderno endecasílabo dactílico, anapéstico o de gaita gallega ha sido documentado en profundidad y extensión en una reciente monografía de José Domínguez Caparrós ${ }^{14}$. En dicho volumen se recoge los primeros trabajos que teorizaban sobre este metro, los debates generados en torno a su constitución, definición y nomenclatura como variedad o subtipo del verso de once sílabas, los ejemplos proporcionados por la crítica y los manuales de métrica hasta ese momento, tanto casuales como uniformes, enfatizando en el punto de giro que representa el poema Pórtico de Rubén Darío. Además, provee un nuevo y ampliado catálogo de autores del siglo Xx que hacen un uso moderno de este tipo de endecasílabo. De manera general, podemos afirmar, junto a la detallada obra de Domínguez Caparrós y la conocida reseña descriptiva e histórica de Tomás Navarro Tomás, que el endecasílabo dactílico está presente, siempre de forma casual, en la lírica española desde sus mismos inicios ${ }^{15}$. Coincidiendo con el criterio de Domínguez Caparrós, no es de nuestro interés extendernos en el uso casual de este metro ni tampoco nos interesa su empleo en la poesía popular ${ }^{16}$.

Como señala Domínguez Caparrós, Pórtico de Darío «marca un hito en la historia de este verso» y divide su empleo en un antes

\footnotetext{
${ }^{9}$ Milá y Fontanals, Manuel: Obras completas, cit.

${ }^{10}$ De la Barra, Eduardo: Nuevos estudios de versificación castellana. Santiago de Chile: Imprenta Cervantes, 1891.

11 Vicuña Cifuentes, Julio: Estudios de métrica española. Santiago de Chile: Editorial Nascimento, 1929.

${ }^{12}$ Henríquez Ureña, Pedro: Obras completas, cit.

13 Navarro Tomás, Tomás: Métrica española, cit.

14 Domínguez Caparrós, José: El moderno endecasílabo dactílico, anapéstico o de gaita gallega. Sevilla: Rhythmica, Revista española de Métrica Comparada. Anejo III, 2009.

15 Navarro Tomás, Tomás: Métrica española, cit., p. 183.

16 Para delimitar los términos uso casual y uso uniforme nos remitimos a una precisión de Domínguez CAPARRós, José: «El endecasílabo dactílico en poesía popular», Rhythmica, 2009, VII, 7, p. 230, en la que expresa que el primero no es más que «la aparición casual entre versos de otra estructura», y el segundo, el uso uniforme, que es el que nos interesa, ocurre «cuando el poema adopta como diseño de todos sus versos el de la estructura del endecasílabo dactílico».
} 
y un después ${ }^{17}$. El poema, el más extenso hasta ese momento en el uso intencional y uniforme del endecasílabo dactílico, cuenta con 152 versos. Pórtico de Darío se convierte de golpe en un ejemplo imprescindible para la legitimación y consolidación de este subtipo de endecasílabo en el corpus métrico hispánico. Después de Darío, varios han sido los poetas, tanto peninsulares como hispanoamericanos, que han empleado este metro. La siguiente tabla, resumen de la monografía de Domínguez Caparrós, expone el corpus de autores, el número de poemas y el número de versos de este metro después del poema de Darío:

\begin{tabular}{|l|c|r|}
\hline \multicolumn{1}{|c|}{ Poeta } & $\begin{array}{c}\text { N. }{ }^{\circ} \text { de } \\
\text { poemas }\end{array}$ & $\begin{array}{c}\text { Total de en- } \\
\text { decasílabos } \\
\text { dactílicos }\end{array}$ \\
\hline S. Rueda & 2 & 22 \\
\hline Zarzuela «Los Tabaqueros» & 1 & 4 \\
\hline M. González Prada & 5 & 68 \\
\hline A. de Zayas & 5 & 220 \\
\hline E. Díez-Canedo & 6 & 112 \\
\hline E. Marquina & 7 & 1893 \\
\hline E. Banchs & 7 & 252 \\
\hline F. Villaespesa & 1 & 20 \\
\hline G. Mistral & 5 & 167 \\
\hline L. Lugones & 1 & 4 \\
\hline D. de la Vega & 2 & 70 \\
\hline J. Guillén & 8 & 107 \\
\hline M. de Unamuno & 1 & 19 \\
\hline M. Hernández & 4 & 90 \\
\hline E. Florit & 1 & 20 \\
\hline R. Alberti & 2 & 52 \\
\hline A. Reyes & 1 & 34 \\
\hline G. Diego & 1 & 40 \\
\hline F. Vighi & 1 & 20 \\
\hline A. Carvajal & 2 & 38 \\
\hline P. Jauralde & 1 & 14 \\
\hline
\end{tabular}

${ }^{17}$ Domínguez Caparrós, José: El moderno endecasílabo, cit., p. 80. 
Actualmente vive en Cuba, aunque publica su poesía en Estados Unidos, un poeta que la crítica local desconoce como tal por razones que exceden los objetivos de este artículo. Por consiguiente, es también ignorado por la crítica iberoamericana. Se trata del poeta, ensayista y narrador Rafael Almanza Alonso (1957). Su labor como intelectual ha sido reconocida sobre todo por su aporte ensayístico, al tener ya en su haber tres volúmenes publicados sobre la obra de José Martí así como una minuciosa monografía sobre el poeta cubano contemporáneo Eliseo Diego ${ }^{18}$. Pero no ha ocurrido lo mismo con su obra poética ${ }^{19}$. No es sino en los primeros años del siglo XXI que aparecen, con décadas de atraso, sus dos poemarios de juventud, publicados por la editorial de autor, radicada en Miami, Ediciones Homagno. Los volúmenes son Libro de Jóveno $(2003)^{20}$ y El Gran Camino de la Vida $(2005)^{21}$. Bajo el sello de estas mismas ediciones acaba de aparecer HymNos (2014) ${ }^{22}$, un homérico himnario que recoge 16 composiciones de este tipo en más de 500 páginas. En Iconos, uno de estos extensos himnos con más de 500 versos, hemos

${ }^{18}$ Almanza Alonso, Rafael: En torno al pensamiento económico de José Martí. La Habana: Ciencias Sociales, 1990; Hombre y tecnología en José Martí. Santiago de Cuba: Editorial Oriente, 2001; Los hechos del Apóstol. Pinar del Río: Ediciones Vitral, 2005; Elíseo diEgo: el juEgo de diEs? La Habana: Letras Cubanas, 2008.

19 Una revisión de las principales fuentes de crítica de poesía en los años 80 y 90 permite verificar que no se menciona, o apenas es mencionado, este autor. A manera de ejemplo, véase la siguiente bibliografía: Arcos, Jorge Luis: «Las palabras son islas. Introducción a la poesía cubana del siglo XX», en Las palabras son islas. Panorama de la poesía cubana siglo XX (1900-1998). La Habana: Letras Cubanas, 1999; BARQUET, Jesús: «Nueve criterios para armar y una conclusión esperanzada», en Jesús Barquet y Norberto Codina (eds.): Poesía cubana del siglo XX. México: FCE, 2002; DorTA, Walfrido: «Estaciones, estados, documentos: panorama de la poesía cubana en los 80 y los 90 del siglo XX», Anales de literatura Hispanoamericana, 2002, vol. 31, pp. 17-38; LóPEZ Lemus, Virgilio: El siglo entero. El discurso poético de la nación cubana en el siglo XX. 1898-2000. Santiago de Cuba: Editorial Oriente, 2008; y del mismo autor: «La literatura cubana entre 1989 y 1999. Panorama de la poesía», en José Antonio Portuondo (Dr.), Cira Romero y Sergio Chaple (coord.): Historia de la literatura cubana. Tomo III. La revolución (1959-1988). La Habana: Instituto de literatura y lingüística «José Antonio Portuondo Valdor», Ministerio de Ciencia, Tecnología y Medio Ambiente, Letras Cubanas, 2008; Cabezas Miranda, Jorge: Proyectos poéticos en Cuba (1959-2000). Alicante: Universidad de Alicante, 2012.

20 Almanza Alonso, Rafael: Libro de Jóveno. Miami: Ediciones Homagno, 2003.

${ }^{21}$ Almanza Alonso, R.: El gran camino de la vida. Miami: Ediciones Homagno, 2005.

22 Almanza Alonso, Rafael: HymNos. Miami: Ediciones Homagno, 2014. 
encontrado de manera uniforme un número importante de endecasílabos dactílicos ${ }^{23}$.

A primera vista es difícil enmarcar la poesía de Rafael Almanza. En sus poemarios conviven en proporciones equivalentes las formas clásicas y las vanguardistas. Es precisamente esta oscilación entre clasicismo y vanguardia uno de los rasgos fundamentales de la poesía de Almanza y, al mismo tiempo, una de las causas que dificulta su clasificación. No es solo que unos poemas estén escritos en formas clásicas y que otros no lo estén, ni tampoco que la distribución de ambos tipos de representación poética haya sido repartida equilibradamente en los tres poemarios hasta ahora publicados, sino que, incluso en uno $\mathrm{u}$ otro tipo de composición, podemos encontrar acopladas formas clásicas dentro de las vanguardistas y formas vanguardistas dentro de las formas clásicas. Ahora bien, en esta convivencia formal, lo primero que llama la atención, como veremos en nuestro análisis, es la abrumadora presencia de todos los tipos de endecasílabos.

Libro de Jóveno (2003) cuenta con 83 poemas. De este total, un poco más de la mitad, 46 poemas, pertenecen a la vertiente formal, y el resto, 37 composiciones, pertenecen a la vertiente no formal ${ }^{24}$. De los 46 poemas escritos en formas, 19 pertenecen

23 También en Virtual, himno de 695 endecasílabos, que sigue en el orden de HymNos a Iconos, encontramos 59 endecasílabos con acentos en $4^{\mathrm{a}}$ y $7^{\mathrm{a}}$.

${ }^{24}$ Al final de este trabajo intentamos dar solución al análisis de la «cuestión formal» en la poesía de Almanza. En sus tres poemarios, la frontera entre verso regular y verso irregular se hace porosa. Por el momento, nos inspiramos en las dos grandes clasificaciones métricas, manejadas de común acuerdo por la crítica, que establecen la existencia en español de la versificación regular y la versificación irregular. Sin embargo, tendremos que hacer al menos una concesión para adaptarnos a las circunstancias compositivas del poeta. Así, lo que llamaremos vertiente formal incluye las formas clásicas, más ciertos poemas que, si bien no son estrictamente regulares, o sea, no reproducen únicamente uno o dos metros de manera sistemática, sí gozan de una regularidad marcada que se orienta generalmente hacia una alta frecuencia de endecasílabos. En segundo lugar, llamaremos, por oposición, vertiente no formal al resto de los poemas, que no queremos llamar libres porque, aunque muestran una acentuada irregularidad métrica, como advertíamos arriba, comparten también una importante cuota de endecasílabos. Hacemos estas salvedades taxonómicas en aras de no dejar de incluir poemas con suficiente regularidad métrica que, de seguir las clasificaciones actuales, caerían en categorías como versificación irregular fluctuante o libre, a pesar de que solo un porciento mínimo de sus versos se alejan del patrón métrico reproducido por el poema en cuestión. 
a textos en endecasílabos: 11 poemas en endecasílabos libres y 8 sonetos. De estos 11 poemas en endecasílabos libres, encontramos 6 de ellos encabezando el poemario en su primera sección, lo que indica un primer llamado de atención hacia el interés de Almanza por este metro. El grupo de poemas de la vertiente formal acumula 837 versos, dentro de los cuales encontramos 523 endecasílabos en sus diversos tipos. Sin embargo, en el segundo grupo de poemas, aquellos de la vertiente no formal, el número de endecasílabos no es tampoco desdeñable. Los poemas sin formas acumulan un total de 1158 versos, de los que al menos casi un tercio, 439 versos, son también endecasílabos. Como vemos, el «elemento clásico» -en este caso, el empleo uniforme del endecasílabo- y el «elemento contemporáneo» están fundidos y marcan la poesía de Almanza desde los inicios de su carrera poética. De los 1995 versos de Libro de Jóveno 962 versos son endecasílabos, por lo que alcanza casi un 50\%, con un claro equilibrio entre poemas de la vertiente formal (523 endecasílabos) y poemas de la vertiente no formal (439 endecasílabos). Con casi un millar de endecasílabos y al menos la mitad del volumen escrito en formas clásicas, Almanza anuncia así la intención de dominar las cuestiones formales, y particularmente este metro ${ }^{25}$.

El panorama del empleo del endecasílabo en El gran camino de la vida (2005), segundo volumen poético de Almanza, varía ligeramente. En relación con Libro de Jóveno (2003), es un volumen en el que la vertiente no formal, o sea, el verso libre o la ausencia de formas predomina más. Sin embargo, los datos que aportamos demuestran que Almanza no ha abandonado su interés por las formas clásicas, y mucho menos por el endecasílabo. El segundo poemario de Almanza cuenta con 96 poemas, de ellos 37 pertenecen a la vertiente formal, y el resto,

$\overline{25}$ El octosílabo, por ejemplo, es el metro que sigue con mayor frecuencia al empleo del endecasílabo. A pesar de que el libro cuenta con una sección central de 24 décimas, obviamente en octosílabos, las estadísticas del metro por excelencia del español se encuentran lejos de las del endecasílabo. Así, dentro de los poemas en formas clásicas encontramos 224 octosílabos, y dentro de los poemas en formas libres sólo 46, para un total de 270 octosílabos, menos de la tercera parte de los endecasílabos contabilizados. Estos datos aseveran nuestras observaciones sobre la preminencia del endecasílabo en Libro de Jóveno. 
59 poemas, a la no formal. Los 37 poemas con formas acumulan 434 versos, y de ellos, las dos terceras partes, 326 versos, son endecasílabos. Como habíamos advertido, los versos sin formas ocupan la mayor parte del libro con un total de 1895 versos, de los que 416 son endecasílabos. De modo que obtenemos para este volumen 2329 versos con o sin formas, en los que encontramos 742 endecasílabos, o sea, unos doscientos endecasílabos menos que en el libro anterior ${ }^{26}$. Aunque el número desciende, sigue siendo considerable si se tiene en cuenta que los endecasílabos representan casi la tercera parte de los versos de este poemario. Debemos apuntar que esta inclinación de la balanza hacia la vertiente no formal, si bien mínimamente pudiera afectar los datos de nuestra intuición formalista a favor del endecasílabo, por otra parte reafirma el carácter contemporáneo de la poesía de Almanza, y sobre todo la espontaneidad y la naturalidad del equilibrio que señalábamos más arriba entre la vertiente formal y la no formal. No obstante, debemos matizar la afirmación anterior recordando que hemos encontrado, una vez más, un número considerable de endecasílabos dentro de la vertiente no formal, lo que nos conduce a seguir considerando el dominio de este metro como un elemento central en la poesía de Almanza.

Antes de dejar atrás sus dos poemarios de juventud y pasar a HymNos (2014), la poesía de madurez de Almanza, creemos conveniente hacer un balance de nuestras observaciones ${ }^{27}$. A tono con el contexto poético contemporáneo, encontramos en estos dos primeros poemarios de Almanza, Libro de Jóveno (2003) y El gran camino de la vida (2005), una poesía marcada por la irregularidad métrica en un buen por ciento, lo que hemos

${ }^{26}$ El balance del octosílabo sigue en franca desventaja en este libro. En los poemas con formas solo encontramos 33 de ellos, y en los poemas sin formas 44, para un total de 77, o sea, aproximadamente un $10 \%$ del total de endecasílabos. Una vez más, en relación con el metro aquí estudiado, confirmamos el interés de Almanza por el endecasílabo.

27 Los poemas de los dos primeros poemarios, Libro de Jóveno (2003) y El gran camino de la vida (2005) están fechados entre 1975 y 1984 para el primero y 1985-1990 para el segundo. Los poemas de HymNos (2014) fueron escritos entre 1991 y el 2008. Como vemos, Almanza, cuyo año de nacimiento es 1957, tiene entre 18 y 27 años cuando escribe su primer poemario; entre 28 y 33 años cuando escribe el segundo y entre 34 y 51 años cuando escribe el tercero y último de los volúmenes hasta ahora publicados. 
llamado su vertiente no formal. Pero, paradójicamente, hallamos una alta frecuencia de endecasílabos, muy por encima de otros metros de nuestra lírica, oscilando, tanto en su vertiente formal como en la no formal, en altos índices de frecuencia métrica que alcanzan casi un $50 \%$ en el primer libro, hasta descender a un poco más del $30 \%$ en el segundo. Si promediamos estos dos volúmenes, podemos concluir que en ambos libros el endecasílabo representa casi el $40 \%$ de la totalidad de los versos, cifra nada desdeñable si consideramos el contexto formal a que ha sido expuesto el endecasílabo tanto en la obra de Almanza como en la poesía contemporánea cubana ${ }^{28}$. Hacemos notar que la cifra de endecasílabos se acerca a casi dos millares, y se incrementará considerablemente con la llegada de HymNos (2014), en el que encontraremos, además, el nuevo caso de uso uniforme del endecasílabo dactílico que pretendemos documentar.

HymNos (2014) es una obra en marcha, un proyecto de himnario mayor que debería alcanzar la cifra total de 24 himnos. En su primera publicación cuenta con 16 himnos repartidos en 536 páginas, que son a su vez una colección de cinco himnarios menores. El primero, Visiones, contiene los cinco primeros himnos: Del Contacto, De la Almendra, Al Sol del Centro, De la Distancia y Desde el Sueño. Iconos, el segundo himnario, contiene los tres himnos Iconos, Virtual y Vórtice. El tercer himnario, Del Amor Divino, está compuesto por un único himno, construido a su vez por 102 sonetos. El cuarto himnario, Adjetivos, contiene los cuatro himnos Memorial, Semejante, Anual y Unánime. El quinto himnario, Áncora, con un único himno del mismo nombre cierra el volumen. Por último, De las Consignas, está compuesto por ocho carteles o pancartas intercaladas a lo largo del himnario ${ }^{29}$.

Como habíamos dicho más arriba, los poemas del libro Iconos son tres: Iconos, Virtual y Vórtice. Los tres himnos y el mismo título apuntan sin dudas al dogma central del cristianismo: la Trinidad. El himnario Iconos abre sus páginas con

${ }^{28}$ De un total de 4334 versos entre los dos volúmenes, 1704 versos son endecasílabos.

${ }^{29}$ Áncora y De las Consignas son a su vez himnos inconclusos textual y audiovisualmente, pero funcionan como unidades de sentido dentro de la presente versión del himnario. 
esta dedicatoria: «En júbilo por la Trinidad que es Dios. Por tanto, en el orden trinitario, el himno Iconos correspondería a la figura del Padre».

Si trazamos una línea entre «tradición» y «vanguardia», podemos agrupar los himnos de Almanza como sigue: por un lado, textos relativamente «tradicionalistas» como los himnos $D e$ la Almendra, Iconos, Virtual, Del Amor Divino, Anual, y por otro lado, textos bastante alejados de la tradición y más cercanos a la experimentación como los himnos Desde el Sueño, Vórtice, Semejante, Unánime y Áncora. Como vemos, HymNos (2014) es un volumen de poesía contemporánea en tanto que maneja códigos que subscriben las tendencias vanguardistas -verbi gratia, códigos visuales en himnos como Desde el Sueño, Vórtice, Semejante y Áncora o códigos aún más vanguardistas como las experiencias performáticas del himno De las Consignas. A su vez, y a tono con el comportamiento de la poesía de Almanza que hasta aquí hemos venido observando, en su vertiente formal, HymNos es un volumen en el que encontramos composiciones con rasgos clásicos suficientes como para contrabalancear el criterio de que solo se trate de poesía de vanguardia. Citemos, por ejemplo, el himno Iconos con 576 endecasílabos en agrupaciones estróficas de extensión puntual, aunque tal combinatoria de versos responde a una arquitectura abierta; el himno Virtual con 695 endecasílabos cuya estructura estrófica crece y decrece reflejándose ambas partes como en un espejo; Del Amor Divino con 1428 endecasílabos repartidos en los 102 sonetos ya mencionados; y Anual con 365 endecasílabos en estrofas de siete versos en arte mayor, variaciones contemporáneas de la poco utilizada séptima o septeto que merecería un artículo aparte. Así, en HymNos encontramos más de 3000 endecasílabos, repartidos en extensos himnos dedicados enteramente al uso de este metro, con una variedad estrófica que no deja tampoco de resultar llamativa. El número de endecasílabos en HymNos, solo en su vertiente formal, se suma así al que hemos venido observando en los dos poemarios anteriores, y se aproxima a la cifra de los 5000 endecasílabos en solo tres volúmenes ${ }^{30}$.

${ }^{30}$ Los tres libros acumulan 4768 endecasílabos, sin contabilizar en ellos los posibles hallazgos de endecasílabos esporádicos entre los poemas de la vertiente no formal 
Como acabamos de revelar, Iconos está compuesto por 576 endecasílabos. En atención a los acentos en $4^{\mathrm{a}}$, en $7^{\mathrm{a}} \mathrm{o}$ en ambas sílabas, veamos cómo quedan repartidos los tipos de endecasílabos que forman este himno. Para los tipos, nos basaremos en los criterios taxonómicos de Varela Merino, Moíno Sánchez y Jauralde $\mathrm{Pou}^{31}$. Por último, como Iconos es un poema extenso, ofreceremos un ejemplo de cada tipo en aras de no hacer tan larga la exposición.

I. Encontramos tan solo 12 versos, es decir $2,08 \%$ de los versos, con acentos en $4^{\mathrm{a}}$ pero sin acentos en $7^{\mathrm{a}}$. Pueden llevar otro acento en $1^{\mathrm{a}}$ y en $2^{\mathrm{a}}$. Aquí presentamos los siguientes ejemplos:

\begin{tabular}{|c|l|c|l|}
\hline N. de verso & \multicolumn{1}{|c|}{ Verso } & \multicolumn{1}{c|}{ Acentos } & \multicolumn{1}{c|}{ Tipo } \\
\hline 24 & Ven y revélame, fascinación! & $1^{\mathrm{a}}, 4^{\mathrm{a}}, 10^{\mathrm{a}}$ & Vacío pleno \\
\hline 134 & Convoco un átomo a tu comunión & $2^{\mathrm{a}}, 4^{\mathrm{a}}, 10^{\mathrm{a}}$ & Vacío heroico \\
\hline 140 & Aniquilándome a tu reverencia & $4^{\mathrm{a}}, 10^{\mathrm{a}}$ & Sáfico difuso $^{32}$ \\
\hline
\end{tabular}

II. Hallamos 98 endecasílabos, o sea $17 \%$ de los versos, con acentos en $7^{\mathrm{a}}$ pero no en $4^{\mathrm{a}}$. Generalmente tienen un acento en $1^{\mathrm{a}}$, aunque pueden llevarlo en $2^{\mathrm{a}}$ como en el segundo ejemplo de la tabla que sigue. El primer caso, el más frecuente de este grupo por cierto, es considerado como «teóricamente posible», y el segundo como un ejemplo de endecasílabo heroico «relativamente usual» pero no «naturalizado» ${ }^{33}$ :

de HymNos como Del Contacto, Al Sol del Centro, De la Distancia, Memorial o Unánime.

31 Valera Merino, Elena, Pablo Moíno Sánchez y Pablo Jauralde Pou: Manual de Métrica española. Madrid: Editorial Castalia, 2005, pp. 113, 181-205.

32 Valera Merino, Elena, Pablo Moíno Sánchez y Pablo Jauralde Pou: Manual de Métrica española. Madrid: Editorial Castalia, 2005, pp. 192. Este tipo es considerado como una variante extrarrítmica del endecasílabo sáfico difuso puro con acentos en $3^{\mathrm{a}}, 4^{\mathrm{a}}$ y $10^{\mathrm{a}}$. Se conoce también como endecasílabo trovadoresco por PARAíso, Isabel: La métrica española en su contexto románico. Madrid: Arco/Libros, 2000, p. 130; por endecasílabo primario (Clarke, Dorothy C.), ver DomínGUEZ CAPARRós, José: Diccionario de métrica española, cit., p. 142; endecasílabo $B$ o $B$ por HenríQuez Ureña, Pedro: Obras completas, cit., p. 158, y por BAEHR, Rudolf: Manual de versificación, cit., pp. 138-139. Habrá que preguntarse si la influencia de un contexto dado puede afectar la efectividad de estas clasificaciones. En Iconos, como veremos, el contexto es más dactílico que vacío o sáfico.

${ }^{33}$ A este respecto ver Valera Merino, Elena, Pablo Moíno Sánchez y Pablo Jauralde Pou: Manual de Métrica española, cit., pp. 185, 196. 


\begin{tabular}{|c|c|c|c|}
\hline $\begin{array}{c}\text { N. }{ }^{\circ} \text { de } \\
\text { verso }\end{array}$ & Verso & Acentos & Tipo \\
\hline 4 & Óbrame en la perfección que me invade & $1^{\mathrm{a}}, 7^{\mathrm{a}}, 10^{\mathrm{a}}$ & $¿ ?$ \\
\hline 60 & Nací para pronunciar tu certeza & $2^{\mathrm{a}}, 7^{\mathrm{a}}, 10^{\mathrm{a}}$ & $¿ ?$ \\
\hline
\end{tabular}

III. En el orden de lo que ha sido llamado propiamente endecasílabo dactílico, con acentos constitutivos en $4^{\mathrm{a}}$ y $7^{\mathrm{a}}$, la primera variante que encontramos es la dactílica pura ${ }^{34}$. Hemos encontrado 139 endecasílabos de este tipo, o sea, 24,13\%:

\begin{tabular}{|c|c|c|c|}
\hline $\begin{array}{c}\text { N. de } \\
\text { verso }\end{array}$ & Verso & Acentos & Tipo \\
\hline 12 & Revelación: igualdad deleitándome & $4^{\mathrm{a}}, 7^{\mathrm{a}}, 10^{\mathrm{a}}$ & Dac. puro \\
\hline
\end{tabular}

IV. La siguiente variante, o endecasílabo dactílico pleno, es la que lleva acentos en $1^{\mathrm{a}}, 4^{\mathrm{a}}, 7^{\mathrm{a}}$ y $10^{\mathrm{a}} 35$. Hemos hallado 277 endecasílabos de este subtipo, o sea, 48,09\%. Casi la mitad del himno Iconos está escrito en este patrón métrico. El hallazgo de esta cifra de endecasílabos plenos, más las variantes pura y corta, nos permite aseverar que, a excepción del ejemplo dramático de Marquina, Iconos sobrepasa en número a todos los ejemplos de uso intencional y uniforme del endecasílabo dactílico:

\begin{tabular}{|c|c|c|c|}
\hline $\begin{array}{c}\text { N. }{ }^{\circ} \text { de } \\
\text { verso }\end{array}$ & Versos & Acentos & Tipo \\
\hline 1 & Nombre de Amor, realidad victoriosa & $1^{\mathrm{a}}, 4^{\mathrm{a}}, 7^{\mathrm{a}}, 10^{\mathrm{a}}$ & Dac. pleno \\
\hline
\end{tabular}

34 También conocido como anapéstico por Milá y Fontanals, Manuel: Obras completas, cit., p. 326; $B$ por HenríQUeZ UReÑA, Pedro: Obras completas, cit., p.158; $B_{3}$ puro italiano por BAEHR, Rudolf: Manual de versificación, cit., p. 141; dactílico por Navarro Tomás, Tomás: Métrica española, cit., p. 504 y dactílico o de gaita gallega por Domínguez CAPARRós, José: Diccionario de métrica española, cit., p. 139.

35 También conocido como anapéstico por Milá y FonTanals, Manuel: Obras completas, cit., p. 326; B, de gaita galaica, gallega o muñeira por HeNRÍQUEZ UREÑA, Pedro: Obras completas, cit., varias páginas; B3 gallego-portugués por BAEHR, Rudolf: Manual de versificación, cit., pp.141-142; dactílico en su forma plena por Navarro Tomás, Tomás: Métrica española, cit., p. 183, y dactílico o de gaita gallega por Domínguez CAPARrós, José: Diccionario de métrica española, cit., p. 139. 
V. Encontramos también, aunque escasos, endecasílabos con acentos en $2^{\mathrm{a}}, 4^{\mathrm{a}}, 7^{\mathrm{a}}$ y $10^{\mathrm{a}}$, denominado endecasílabo dactílico corto. Hemos hallado 14 endecasílabos de este tipo, o sea, $2,43 \%$. Algunos de ellos presentan un acento en $1^{\mathrm{a}}$ inmediato a la $2^{\mathrm{a}}$ sílaba:

\begin{tabular}{|c|c|c|c|}
\hline $\begin{array}{c}\mathrm{N}^{\circ}{ }^{\circ} \text { de } \\
\text { verso }\end{array}$ & Verso & Acentos & Tipo \\
\hline 52 & Yo soy la escuadra, el compás, el planeta & $1^{\mathrm{a}}, 2^{\mathrm{a}}, 4^{\mathrm{a}}, 7^{\mathrm{a}}, 10^{\mathrm{a}}$ & \multirow{2}{*}{ Dac. corto } \\
\hline 305 & Razón de Amor, sustantivo primero & $2^{\mathrm{a}}, 4^{\mathrm{a}}, 7^{\mathrm{a}}, 10^{\mathrm{a}}$ & \\
\hline
\end{tabular}

Para alcanzar la suma de 576 endecasílabos, faltan a nuestro cómputo 36 versos. Estos endecasílabos, o se constituyen como otra de las variantes del endecasílabo, o presentan los llamados acentos extramétricos o paramétricos por lo que, para los fines documentales de esta descripción métrica introductoria del himno Iconos, hemos decidido no detenernos en ellos.

Finalmente, veamos estos datos en conjunto: 430 endecasílabos dactílicos puros, plenos o cortos estrictamente, para un $74,65 \%$, contra 146 endecasílabos de «otro tipo», o sea $25,34 \%$, aunque comparten en su mayoría al menos uno de los acentos constitutivos del dactílico, el acento en $4^{\mathrm{a}}$ o el acento en $7^{\mathrm{a}}$ sílaba, o los dos. Sin dudas, el número de endecasílabos dactílicos es el más alto hasta ahora observado en poesía lírica en un único texto, si exceptuamos el caso de Marquina cuyo texto es poesía dramática ${ }^{36}$. Pero tampoco deja de interesarnos esa cuarta parte de los endecasílabos de Iconos que, si bien conservan acentos en $4^{\mathrm{a}}$ o $7^{\mathrm{a}}$ sílabas, o en ambas, no son «puramente» dactílicos. Por el momento, dejaremos esa incógnita pendiente para el final de este análisis. Mientras, conviene hacernos otras preguntas: ¿acaso el tema de este himno justifica el empleo de esta variante de endecasílabo? ¿Y su extensión? Creemos que sí y para demostrarlo debemos volver a HymNos.

$\overline{36}$ No tenemos inconveniente alguno en incluir la poesía dramática en el corpus, siempre que la búsqueda y hallazgo de este tipo de endecasílabo se extienda a todos los poetas dramáticos de la lengua española. De hacerlo, las fronteras de esta exploración se extenderían considerablemente, por lo que, en nuestro caso, preferimos mantenernos, por el momento, dentro de los márgenes de la poesía lírica. 
La propuesta estética de Almanza destaca por su complejidad y a su vez por su sencillez. Además, literalmente por su universalidad: la re-unión de los contrarios u opuestos: el orden y el caos, la forma y lo informe, la materia y el espíritu, la realidad y la ficción, el bien y el mal, el cielo y la tierra, Dios y el Hombre, el Yo y el Otro. Propuesta ontológica, filosófica, teológica, antropológica, pero también poemática, estrófica y métrica. En nuestros predios formales, el contenido de ese mensaje se reflejará en la conciliación de los antagonismos como tradición y vanguardia, palabra e imagen, serie poética y autonomía del verso, verso tradicional y verso libre. De ahí que su obra de ficción crezca bajo el nombre del proyecto vitalicio El Amor Universal, puesto que el Amor en Almanza es el ligamento para la reconciliación de todos estos enemigos.

El título de HymNos es un anagrama que encierra tres sentidos. Significa tanto himnos, en su acepción literal, como himeneos, en su acepción anagramática (HymNos: Hym(ENE)os. De modo que el título del himnario propone tres significados en un término: himnos, como composiciones poéticas, himeneos, también como composiciones poéticas, e himeneos, como nupcias. Las bodas que se celebran en estos himnos e himeneos son el elemento clave para desentrañar el sentido del himnario pues nos ofrecen la pista interpretativa fundamental de muchos aspectos en diversos planos. Los primeros son las bodas del Tú $y$ del Yo.

El protagonismo de los pronombres Tú y Yo da sentido al constante empleo del Sí, adverbio de afirmación de toda boda. Otro pronombre se incorpora a esta ceremonia: el Nos, cuya importancia delata el mismo título HymNos.

Afortunadamente Iconos es el himno que estadísticamente cuenta con mayor presencia del Tú. Lo encontramos en 53 versos. El explícito protagonismo del pronombre Tú destaca en relación con el Yo. Si descontamos sus apariciones implícitas como sujeto omitido, el Yo sólo se manifiesta explícitamente en ocho ocasiones. El Sí nupcial aparece en 16 ocasiones en Iconos. El balance de las observaciones de estos monosílabos en Iconos confirman, en primer lugar, la importancia de estos en el proyecto poético de HymNos. En segundo lugar, arrojan una 
frecuencia de apariciones a favor del Tú, lo que se justifica si recordamos que el Yo está en el Tú por la unión de los contrarios. Como vemos, sobre la sencillez o la economía de estos monosílabos descansa todo un volumen de 536 páginas y sus extensos himnos. Tal sencillez no merma la «nupcialidad» significativa, pues precisamente su condición deíctica les permite «matrimoniar» o re-unir infinitas significaciones. Sería una interpretación desdichada reducir el Yo de Almanza a simple yo poético, sin que por ello deje de serlo, por cierto; el Tú a la divinidad, cristiana o griega, el Nos a la mera comunión de estos entes y el Amor al amor cristiano o al amor griego. La indistinción del Tú en Almanza, y de los otros monosílabos mencionados, son la huella de esta singular diversidad de significados. Aprovechan la dimensión de lo sagrado en la realidad en toda su amplitud y apuntan a un sentido polifónico, a una pluralidad significativa en la singularidad. Así como el título del volumen puede ser uno y tres a la vez, del mismo modo la realidad puede significar lo que por mera apariencia es, y además ser huella inefable de Otra realidad. Del mismo modo, la diversidad y escisión que constituyen los pronombres Tú y Yo, se hacen unidad por el Sí nupcial para ser Nos. Un(o y d)iverso, parece ser la sencilla propuesta poética de Almanza: una estética de la conjunción. De ahí que, a la luz de estas interpretaciones, podamos justificar sus elecciones formales. Si no podemos decir que el tópico de la universalidad es novedoso, sí lo son los medios formales para expresarlo en Almanza $^{37}$. Desde esta perspectiva, la convivencia, hasta ahora observada, entre lo «tradicional» y lo «contemporáneo» se vuelve totalmente natural y coherente, necesaria entre la significación de la poesía de Almanza y la elección de los significantes formales. Para Iconos, el caso que nos ocupa, la selección de la forma cumple también con esta matriz.

Nos habíamos propuesto hallar razón para la extensión de Iconos, que asciende a 576 endecasílabos. Tal número se debe a que 576 es el cuadrado de 24 . La propia cifra en sí es revelada en uno de los endecasílabos: Sí: 24 laureles atléticos (v. 419). $\mathrm{Si}$, como vamos exponiendo, convenimos en que la propuesta de

$\overline{37}$ Por ejemplo, Nicolas de Cusa (1401-1464) habla de coincidentia oppositorum. 
Almanza consiste en la conjunción, en la reunión de los opuestos o contrarios, la unión entre orden y desorden (caos) forma parte de las nupcias. Acorde con esta visión integradora del universo en Almanza, con su creencia en una realidad «caóticamente ordenada», la cifra 24, así como otras correlativas -su cuadrado, la mitad 12, el 6, el 4, el 3, el 8, etc.- estructuran numerológicamente Iconos, e HymNos (2014) ${ }^{38}$.

Iconos está compuesto por un chorro de versos esticomíticos, independientes, autónomos, que pueden funcionar cada uno como una unidad de significado. De modo que, cada verso es un poema en sí mismo. La versión que se ofrece es una posibilidad entre tantas, como lo indica una nota al inicio del poema ${ }^{39}$. Los versos de Iconos están distribuidos 11 versos-aislados o versos-poemas y en 44 agrupaciones estróficas de diversos tamaños que establecen una proporcionalidad numérica en función de las claves numerológicas que antes mencionábamos. Los ritmos de agrupamiento estrófico crecen con ritmo propio. Por ejemplo: tres primeras páginas de tres únicos versos respectivamente, tres siguientes páginas con tres tercetos cada una, tres otras páginas con totales de 18 versos, separados en agrupaciones de nueve versos, tres siguientes páginas que acumulan 24 versos con agrupaciones estróficas que oscilan entre seis y cuatro versos, etc. Una elemental disposición de las cifras de este crecimiento estrófico pudieran ser: 1, 3, 4, 6, 9, 12, 18, 24, 25. Una observación pertinente ahora es la siguiente: si hemos llamado agrupaciones estróficas a las estructuras supraversales de Iconos, o sea, a aquellas estructuras intermedias que se encuentran en el camino que va del verso al poema, ha sido porque consideramos que no han sido concebidas como estrofas tradicionales, y de hecho no lo son, sino que, como agrupaciones de versos, «recuerdan», según sea su número de versos, tercetos (no encadenados por la rima), cuartetos, serventesios, sextetos, novenas, etc. ¿Qué sentido tiene entonces agrupar versos autónomos que

\footnotetext{
$\overline{38}$ Recordemos, por ejemplo, que están previstos 24 himnos. En el orden biográfico, Almanza nace un 24 de marzo, tercer mes del año.

39 La nota de la página 107 de HymNos (2014) dice: «Primera versión de autor. El lector puede escoger sus iconos y/o diseñar, meditar, garabatear, colorear, ideogramizar o rezar su(s) propio(s) iconostasio(s)».
} 
no constituyen en definitiva una estrofa pero que proponen otra manera de agrupar versos -temática, sintáctica, visual, etc.? No debemos perder de vista la autonomía de los endecasílabos de Iconos. Arcadio Pardo ha demostrado con numerosos ejemplos la independencia que puede alcanzar el verso ante la serie versal ${ }^{40}$. No hay serie en Iconos, al menos no como tradicionalmente se le conoce, porque cada verso reclama su propia unidad, como un icono. Su oración está contenida dentro de los límites de cada uno de los 576 versos. Pueden ser un verso fuera de la serie o agruparse como el lector lo desee, tal como lo propone el poeta. Pero estos iconos autónomos o esticomíticos no anulan la serie, más bien la generan de otro modo, con otra discursividad ${ }^{41}$. Esta nueva discursividad autónoma de cada icono del poema permite conservar, a pesar de la falta de contigüidad oracional, la unidad de la nueva serie. Permite además otro agrupamiento estrófico, parecido al que hemos conocido hasta ahora en los manuales de métrica, pero definitivamente diferente. La esticomitia, como recurso, «desune» estos grupos de versos. La ausencia de rima parece colaborar con esta aparente falta de unión. La rima cero, como se le conoce, no es más que la carencia de rima, y se sabe que su ausencia no afecta la unidad estrófica ${ }^{42}$. En Iconos, el 0 o la ausencia de rima, la cifra que no es, que no se ve, en fin, la figura del Padre, hace de rima. Pero también el tema, las estructuras sintácticas, el metro, el aspecto visual «reúnen» los versos de estos grupos. Por último, como colofón antiestrófico, encontramos la extensa estrofa final que ocupa varias páginas, después de todo el primer esfuerzo de organización estrófica del poema.

$\overline{40}$ Sobre la cuestión de considerar un único verso como un verso-poema véase el artículo de PARDO, Arcadio: «Verso aislado, verso solo, verso-poema». Rhythmica, 2004, II, 2, pp. 201-233.

${ }^{41}$ Queda por definir lo que se entiende por serie. Dice PARDO: «Muchos tratadistas, como se ha visto, sólo consideran verso a aquel que se encuentra incluido en una serie, sin que el concepto de serie quede totalmente definido», ibid., p. 221. Y sugiere: «Bien pudiera ser que [...] la serie se establezca, no únicamente en el poema, sino entre versos [que] tienen entre si algo compartido en el asunto de que se trata y/o en la expresión». Por último, agrega: «Apoya, además, esta pertenencia a la misma familia, el hecho de que estos versos se sitúen siempre en igual posición y adopten una estructura lingüística paralela», ibid., p. 224.

42 Según Balbín, Rafael de: Sistema de rítmica española. Madrid: Gredos, 1975. Tercera edición, p. 248, la llamada rima cero «no destruye el sistema rítmico de la unidad estrófica». 
Empieza Iconos con un impulso estrófico cercano, pero sin serlo propiamente, al de los poemas estróficos, para luego precipitarse hacia el extremo opuesto y culminar, recordándonos algo de romance de arte mayor no rimado, como una cima del antiestrofismo. Es una reconciliación de contrarios. No debemos, por último, olvidar el aspecto visual de las agrupaciones estróficas de Iconos. La acumulación o aislamiento de los versos en función del 24 y sus múltiplos, el desplazamiento o no de los versos en cada agrupación, su versión en poema objeto, son algunos de los elementos que hacen de Iconos un poema visual también. Iconos propone también la re-unión de lo verbal y lo visual ${ }^{43}$.

Si Iconos se propone reconciliar la serie con el verso solo, el poema estrófico con el poema no estrófico, la rima con su ausencia, la palabra con la imagen, supuestamente debería también reflejarse en la elección de su metro ese principio reunificador.

Recordemos que se trata de un verso cuyo ritmo es ternario, o sea, el tres en el uno, como la Trinidad, como el Padre, como los Iconos. Notemos además que, en atención a la arquitectura numerológica de la poesía de Almanza, en el caso del endecasílabo dactílico, si descontamos el acento en $10^{\mathrm{a}}$, común a todos los subtipos de este metro, los acentos en $4^{\mathrm{a}}$ y $7^{\mathrm{a}}$ de su forma pura son los únicos que reproducen indirectamente, como una fineza aritmética, la longitud del metro escogido, o sea, suman 11. También, por su propio ritmo, ha sido clasificado como un metro «falto de gravedad», por lo que parecería poco conveniente para un tipo de poesía cuya temática grave es lo sagrado, razón de más, si nos atenemos al comportamiento poético de Almanza -reunión de contrarios- para recurrir a este metro ${ }^{44}$.

Ahora bien, no solo estas particularidades del endecasílabo dactílico convienen a Iconos. La esporádica o poca frecuencia de uso del endecasílabo dactílico en la poesía testimonia de la incertidumbre de su naturaleza y del debate métrico que esta variante de endecasílabo ha generado. No vamos a detenernos en los detalles teóricos que Domínguez Caparrós ha recogido

\footnotetext{
${ }^{43}$ Dos de las versiones de los himnos de Iconos, el Iconostasio y Vórtice-poema video, han sido exhibidas como poemas objeto en la exposición Teatro Universal que tuvo lugar en Centro de Desarrollo de las Artes Visuales en La Habana, entre el 12 de septiembre y el 12 de octubre del 2014.

${ }^{44}$ Domínguez CAPARrós, José: Diccionario de métrica española, cit., p.139.
} 
detalladamente en su reciente monografía ${ }^{45}$. Señalemos tan solo que la legitimidad de este endecasílabo en lengua española ha sido disputada tempranamente por el verso de arte mayor como dodecasílabo. Milá y Fontanals encabeza su trabajo intentado hacer las primeras distinciones: Esta semejanza de construcción [la del dodecasílabo] nos explica hasta cierto punto el hecho de que el dodecasílabo, aunque compuesto de lesbios, se asocie muy bien con los otros dos versos [el endecasílabo] que son anapésticos $^{46}$. También nos recuerda que el uso casual de esta variante del endecasílabo, mezclado con otros metros, hizo su parte: En los tiempos antiguos hallamos muchos endecasilabos que lo tienen en la cuarta y en la séptima, es decir casualmente anapésticos, mezclados con otros de acentuación diferente ${ }^{47}$. Estamos en presencia de un endecasílabo arcaico y periférico que hallamos en la frontera formal. A tono con lo que hemos observado hasta ahora en la poética de Iconos, es justamente ese aspecto de «hijo pródigo» formal el que más conviene a la coherencia de la propuesta poética de Almanza.

Ahora bien, nos queda un último punto por reconciliar. Si recordamos los equiparables porcientos de versos regulares e irregulares de la poesía de Almanza, convendremos en que no aspira a ser totalmente formalista o antiformalista. Sin embargo, el análisis métrico de su poesía parece no tener otro camino que estudiar su vertiente formal y antiformal por separado, como dos sistemas métricos diferentes en el que se cruzan la poesía tradicional en la figura del endecasílabo y la no tradicional en la figura del verso libre. Si la reconciliación, el principio nupcial, se encuentra en la base de su poética, y por lo tanto, de su métrica ¿Cómo es que la teoría métrica debe renunciar a explicar su métrica desde esta perspectiva reconciliadora? ¿Tendremos que estudiar, por separado, los endecasílabos de Almanza dentro del conocido silabotonismo, por ejemplo, y el verso libre dentro de las teorías del verso moderno a ese respecto? A menos que encontremos una teoría métrica que reúna el endecasílabo y el verso libre de Almanza.

\footnotetext{
${ }^{45}$ Domínguez Caparrós, José: El endecasilabo dactílico, cit.

${ }^{46}$ Milá y FontanAls, Manuel: Obras completas, cit., p. 326-327.

47 Ibid., p. 335
} 
Oldřich Bělič ha propuesto que el verso español es un verso variable $^{48}$. Consideraciones sobre la segmentación, la entonación, la prosodia española, el carácter objetivo y a la vez subjetivo del verso son los aspectos básicos de su teoría. Bělič concentra su análisis en el llamado verso regular. Este tipo de verso estaría situado a medio camino entre los sistemas rítmicos silábico y silabotónico, aunque más cerca del segundo que del primero, a tal punto que conviven ${ }^{49}$. A excepción del sistema métrico silábico, del que toma como referencia el del francés clásico, la teoría del hispanista checo no niega rotundamente la existencia en la poesía española de los sistemas métricos cuantitativo, acentual o tónico, silabotónico o libre, tal como han sido descritos hasta ahora ${ }^{50}$. Más bien considera que, dentro de las manifestaciones concretas de alguno de estos sistemas, subyace otro, como una invariante, que él llama verso con acentuación variable o verso variable ${ }^{51}$. A diferencia de los versos europeos cuantitativo, acentual, silábico, silabotónico y libre, lo distintivo del verso variable español es «el número y la repartición variables de sus acentos interiores» ${ }^{52}$. Según Bělič, en el verso español se dan varias tensiones, sobre todo, una tensión entre la fonología oracional, o sea, el acento oracional o cumbre de intensidad que haya su correspondencia también en el mismo lugar del periodo rítmico del verso, y cuya energía se expande desde su máximo en la cláusula rítmica final obligada, siempre

$\overline{48}$ BĚLIČ, Oldřich: Verso español y verso europeo. Introducción a la teoría del verso español en el contexto europeo. Santafé de Bogotá: Instituto Caro y Cuervo, 2000.

${ }^{49}$ Ibid., pp. 543-545.

${ }^{50} \mathrm{Ibid}$., pp. 603-604. Ver resumen sobre la existencia o no de estos sistemas en la poesía española.

${ }^{51}$ En realidad este tipo de verso ya había sido enunciado por otros tratadistas bajo el nombre, por ejemplo, de metro de periodo mixto en Navarro Tomás, Tomás: Métrica española, cit., p. 11 o de verso polirrítmico en BALBín, Rafael de: Sistema de rítmica castellana, cit., pp. 143-146. Ver también en DomíNGUEZ CAPARRós, José: Diccionario de Métrica, cit., p. 483. En el caso de Bělič la diferencia con sus antecesores es, primero, de grado, pues lo que para unos era accidental o secundario, para Bělič es la forma esencial del verso español. En segundo lugar, ninguno de los autores que le precedieron pusieron énfasis en un enfoque semántico del verso, cosa que sí hace Bělič y con ello cambia la fisonomía del modelo métrico, o sea, se aleja bastante de lo que los otros autores, todavía basados en los pies métricos, consideraban como mixto o polirrítmico.

52 BĚLIČ, Oldřich: Verso español y verso europeo, cit., p. 515. 
del tipo U-U, y la fonología de la palabra, cuyo único elemento -el(los) acento(s) prosódico(s) en la(s) palabra(s) o los grupos de intensidad, sílabas atonas que en torno a él se forman-genera otra onda energética de signo opuesto. La «onda» fruto de la fonología oracional recorre el verso y tiende a disminuir desde su final hacia el principio del mismo; la «onda» proveniente de la fonología de la(s) palabra(s) se desplaza a su vez y tiende a disminuir desde el principio del verso hacia su final. El fuerte acento léxico del español, con su importante carga fonológica, compite con el fuerte acento oracional de la lengua, «disputándose» ambos el protagonismo. Paradójica y dialécticamente, esta competencia se resuelve también en cooperación, en unidad. Afortunadamente también, ambas energías se ven favorecidas por «la debilidad de las señales demarcativas» del español -los fenómenos de la sinalefa y el enlace son pruebas de ello-, lo que contribuye también a dar unidad al verso.

Ahora bien, la irregularidad o variabilidad de estos acentos no es tampoco del todo libre. Queda «atada» a determinada regularidad:

La norma rítmica del verso común [variable] consiste, como sabemos, en la cláusula acentual [final obligatoria] y un determinado número de sílabas. La norma representa la regularidad, y los acentos interiores, que no están sujetos a norma, la irregularidad. En el verso común [variable] hay, por tanto, combinación o síntesis de la regularidad o la irregularidad; o de la periodicidad y la no periodicidad ${ }^{53}$.

Pero la constitución del verso variable es más compleja y trasciende las meras cuestiones fónicas. Como vimos, la intensidad de tal tensión depende de determinada extensión silábica y además «tiene algo que ver con el aspecto semántico»: a diferencia del sistema silabotónico, en el verso común [Bělič después lo llamará variable] no hay ningún divorcio entre el ritmo y el significado $^{54}$. Esta última característica es importante porque, primero, resuelve de golpe el problema de la condición asemántica de los llamados pies métricos, ajenos a la natural constitución de la lengua y por lo tanto imposibles de percibir por los no

\footnotetext{
53 Ibid., pp. 510-511. El subrayado es nuestro.

${ }^{54}$ Ibid., pp. 508, 513.
} 
iniciados; segundo, con la desaparición de estos últimos, legitima con base teórica la existencia y naturalidad de los llamados acentos extramétricos o paramétricos y, por último, propone un verso variable cuya flexibilidad se adapta a las exigencias semánticas naturales de la cadena lingüística del español, por lo que se hace más perceptible o agradable al oído común ${ }^{55}$.

En resumen, en el verso variable confluyen

[...] los elementos de la fonología oracional, los no-fonológicos y el único elemento relevante de la fonología de la palabra [...] Entre este tipo de verso y el idioma hay una adhesión perfecta. No hay problemas con los comienzos (anacrusis) y los versos con sinalefa; hay identidad entre el verso como idioma y el verso como ritmo. Hay un semantismo natural, sin obstáculos ${ }^{56}$.

Como habíamos sugerido más arriba, la propuesta teórica de Bělič no riñe del todo con otros sistemas métricos, extrayendo de ellos una invariante para el verso español, el verso variable ${ }^{57}$. Esta no solo puede ser legítima en un contexto de condiciones silabotónicas como el del endecasílabo dactílico en Iconos, sino que se puede aplicar a los otros sistemas rítmicos, entre ellos el verso libre ${ }^{58}$. Las particularidades del verso variable no excluyen para nada contemplar el verso irregular o libre como una de sus posibles ejecuciones ${ }^{59}$. Todo lo contrario, la propuesta teórica del verso variable más bien reconcilia el verso libre con el verso regular y los reúne bajo un mismo paraguas conceptual:

El verso libre no existe fuera de la lengua. Su esencia es, pues, igual a la del verso regular. Difiere de él por la ausencia de ciertos atributos de éste, y también de ciertos convencionalismos: en él no hay, p. ej., el problema de los comienzos de los versos (anacrusis) ni de sus finales, de las sinalefas, de los pies abstractos. Pero comparte

$\overline{55}$ Ibid., p. 546.

56 Ibid., p. 608.

${ }^{57}$ Por otra parte, como Bělič utiliza la métrica comparada, incluso a nivel poemático, la variabilidad o irregularidad de los acentos puede ser constatada doblemente. Es una variabilidad horizontal cuando el verso no reparte las sílabas no acentuadas equitativamente, de dos en dos, por ejemplo. Es una variabilidad vertical cuando en la serie los versos no comparten la regularidad acentual.

58 BĚLič, Oldřich: Verso español y verso europeo, cit., p. 545.

59 Ver consideraciones del capítulo dedicado al verso libre, ibid., pp. 552-602. 
con el verso regular el principio básico de la segmentación específica; y ésta lo separa, a su vez, de la prosa ${ }^{60}$.

Estas consideraciones teóricas resuelven el problema planteado sobre qué perspectiva asumir a la hora de estudiar con una herramienta unitiva la convivencia del endecasílabo y el verso libre que encontramos, en proporciones similares, en la poesía de Almanza. El verso variable propuesto por Bělič cumple con el principio nupcial de la poesía de Almanza, puesto que constituye una reunión de contrarios, una síntesis dialéctica entre regularidad e irregularidad. La variabilidad acentual dentro de la propuesta de regularidad de la norma dactílica que hemos venido observando en Iconos no era otra cosa que la prueba de la manifestación natural del verso variable descrito por Bělič. Nos atrevemos a decir incluso que Iconos no es un poema mayoritariamente en endecasílabos dactílicos sino que es un poema en endecasílabos con acentuación variable, a pesar de su marcado silabotonismo.

Por otro lado, con el verso variable quedan incluido verso regular y verso irregular, verso endecasílabo y verso libre para el caso de Almanza, en un único sistema métrico. Por tanto, el concepto de verso variable constituye la herramienta que necesitábamos y su aplicación a la poesía de Almanza, regular e irregular, una consolidación de su validez.

Finalmente, con este ejercicio queremos comprobar los presupuestos estróficos de Iconos y verificar la existencia del verso variable, incluso en un contexto como este, altamente silabotónico. Veamos los seis primeros y los seis últimos versos de Iconos:

Nómbre de Amór, realidád victoriósa

Úno verbál, dualidád de tus lábios

Gíra la lúz: tu jornáda me acréce

Óbrame en la perfección que me inváde

Dádiva de pretensiónes legítimas 5

Único imán de mi entréga que ofrézco

$\begin{array}{llll}5 & 1 & 7 & 10\end{array}$

Ámbitos! Áncha demóra de tí!

Pádre, otórgame el nómbre que llévo

$\begin{array}{llll}1 & 4 & 7 & 10\end{array}$

$\begin{array}{llll}1 & 4 & 7 & 10\end{array}$

$\begin{array}{llll}1 & 4 & 7 & 10\end{array}$

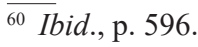


Más! Demandándo en mi muérte, la Vída!

Hé concluído el mirár! Y retórno!

Ícono póstumo, cárta selláda?

575

Nómbrame yá, victorióso de Amór...

$\begin{array}{llll}1 & 4 & 7 & 10 \\ 1 & 4 & 7 & 10 \\ 1 & 4 & 7 & 10 \\ 1 & 4 & 7 & 10\end{array}$

Con la selección de estos dos fragmentos, podemos apreciar en primer lugar que los versos mantienen una unidad poemática a pesar de su autonomía. Por otra parte, tenemos 12 versos que totalizan 132 sílabas. Si el ritmo es dactílico, tenemos 36 acentos potenciales, de ellos 34 realizados y solo 2 sin realizar. La conclusión es, sin dudas, que se trata de ritmo silabotónico: 11 sílabas con acentos regularmente distribuidos en tres pies dáctilos y un pie troqueo final. La variabilidad queda reducida a 2 versos y a 2 acentos no realizados. Parecería no haber modo de poner en duda, en el ejercicio anterior y en las estadísticas del himno, la prevalencia del dáctilo, aunque el aparente intento de regularidad dactílica en Iconos se logra a costa de demostrar que no es del todo posible, como lo demuestra el hecho de que una cuarta parte de los endecasílabos de este himno no sean dactílicos según la norma y que casi el mismo porciento de este fragmento, los versos 4 y 5 , no lo sean tampoco.

Pero el mérito que hasta este punto estamos otorgando al supuesto silabotonismo dactílico de Iconos tiene su talón de Aquiles. Hemos dejado para el final un elemento de la teoría de Bělič sobre el verso variable. Se trata de un rasgo que lo opone al ritmo de pies silabotónicos: el semantismo. ¿Son realmente los pies dactílicos los encargados de generar el ritmo junto a la medida silábica en estos versos? Nos bastará uno de los dos primeros fragmentos anteriores para poner en duda la condición «dactílica». En la siguiente tabla, encontraremos los seis primeros versos de Iconos, divididos según el esquema en pies dactílicos:

\begin{tabular}{|l|}
\hline Segmentación silabotónica en pies dactílicos \\
\hline NómbredeA mórreali dádvicto riósa \\
\hline Únover bálduali dáddetus lábios \\
\hline Gírala lúztujor nádamea créce \\
\hline Óbrameen ¿laperfec? ciónquemein váde \\
\hline
\end{tabular}




\begin{tabular}{|l|}
\hline Dádiva ¿depreten ${ }^{61}$ siónesle gítimas \\
\hline Únicoi mándemien trégaqueo frézco \\
\hline
\end{tabular}

Como sugiere Bělič, el patrón de pie dactílico, y de todos los pies sobre los que está construido el silabotonismo, es mayoritariamente asemántico. Hay un desajuste constante entre los pies y las unidades del lenguaje, lo que no impide que eventualmente pueda haber una coincidencia entre pie y unidad lingüística. La pregunta no es nueva: ¿es posible que alguien escuche o lea los pies más allá de los iniciados en estas materias? La respuesta es no, al menos conscientemente ¿Cómo es que la poesía es legitimada por los lectores ajenos a estas «ingenierías»? ¿Simplemente porque, aunque ajenos, encuentran una musicalidad grata al oído que se introduce en ellos a sus espaldas? Si la respuesta a la primera pregunta parecía obvia, la segunda resulta demasiado simple. A menos que los pies, como ya se sospecha, sean una realidad abstracta al lenguaje, una imposición ajena. Si los pies son estructuras abstractas, irreconocibles por los neófitos, entonces el sistema silabotónico estaría condenado a expresarse aquí sobre conceptos ajenos, por no decir falsos. Si estos endecasílabos no son dactílicos -acabamos de decir que no existen los pies por lo que el pie dáctilo no existe-, ¿qué son?

En la siguiente tabla encontraremos los mismos versos según una propuesta de esquema semántico, divididos en unidades lingüísticas - palabras o grupos de intensidad-en torno a un acento:

\begin{tabular}{|l|}
\hline $\begin{array}{l}\text { Segmentación en palabras o grupos de intensidad en torno a } \\
\text { un acento }\end{array}$ \\
\hline$[$ Nómbre $][$ de Amór $],[$ realidád $][$ victoriósa $]$ \\
\hline$[$ Úno $][$ verbál $],[$ dualidád $][$ de tus lábios $]$ \\
\hline$[$ Gíra $][$ la lúz $]:$ [tu jornáda $][$ me acréce $]$ \\
\hline$[$ Óbrame $][$ en la perfección $][$ que me inváde $]$ \\
\hline$[$ Dádiva $][$ de pretensiónes $][$ legítimas $]$ \\
\hline$[$ Único $][$ imán $][$ de mi entréga $][$ que ofrézco $]$ \\
\hline
\end{tabular}

$\overline{{ }^{61}}$ Como estas sílabas no constituyen un pie dactílico, a menos que convengamos en colocar arbitrariamente un acento secundario, colocamos los signos de interrogación como recordatorio de la irregularidad y de la imposibilidad silabotónica en estos casos. 
Intentamos que los segmentos se ajustaran con naturalidad a las palabras o a los grupos de intensidad, al código lingüístico. Obviamente, esto ocurre en torno a los acentos, por lo que podíamos estar tentados a decir, si ya decidimos renunciar al silabotonismo, que entonces el sistema métrico a emplear sería el tónico o acentual. Chocamos entonces con la, aunque mínima, variabilidad acentual de los versos. Los versos 4 y 5 incumplen con la regularidad acentual al tener 3 acentos, en vez de 4 como el resto de los versos del fragmento, y el número de sílabas atonas entre ellos varía como consecuencia lógica de su cantidad. No hay por tanto absoluta regularidad acentual. El sistema métrico tónico o acentual no sería tampoco el más adecuado porque la cantidad de sílabas no varía, por lo que la regularidad silábica nos obliga a regresar al silabotonismo, que habíamos descartado por marchar totalmente desajustado con el lenguaje y, por ende, ser imperceptible al oído del lector. Por último, la presencia de la misma irregularidad acentual nos impide considerar estos versos dentro del sistema métrico silábico únicamente.

Pues bien, si consideramos entonces que el ritmo de 4 o de 3 segmentos, que probablemente sí percibe el lector no iniciado, no proviene de los pies sino de las propias palabras o de los grupos de intensidad del lenguaje, encontramos una solución que no es del todo ni silábica, ni tónica, ni silabotónica:

\begin{tabular}{|l|l|l|}
\hline \multicolumn{1}{|c|}{$\begin{array}{c}\text { Segmentación en palabras o grupos } \\
\text { de intensidad en torno a un acento }\end{array}$} & $\begin{array}{c}\text { Esquema de } \\
\text { palabras o grupos } \\
\text { semánticos en torno } \\
\text { a un acento }\end{array}$ & $\begin{array}{c}\text { Esquema } \\
\text { silabotónico de } \\
\text { pies dactílicos }\end{array}$ \\
\hline$[$ Nómbre $][$ de Amór $],[$ realidád $][$ victoriósa $]$ & Óo oÓ ooÓ ooÓo & Óoo Óoo Óoo Óo \\
\hline$[$ Úno $][$ verbál], $[$ dualidád $][$ de tus lábios $]$ & Óo oÓ ooÓ ooÓo & Óoo Óoo Óoo Óo \\
\hline$[$ Gíra $][$ la lúz]: [tu jornáda $][$ me acréce $]$ & Óo oÓ ooÓo oÓo & Óoo Óoo Óoo Óo \\
\hline$[$ Óbrame $][$ en la perfección $][$ que me inváde $]$ & Óoo-ooooÓ ooÓo & Óoo ¿ooo? Óoo Óo \\
\hline$[$ Dádiva $][$ de pretensiónes $][$ legítimas $]$ & Óoo oooÓo oÓo & Óoo ¿ooo? Óoo Óo \\
\hline$[$ Único $][$ imán $][$ de mi entréga $][$ que ofrézco $]$ & Óoo-oÓ ooÓo oÓo ${ }^{62}$ & Óoo Óoo Óoo Óo \\
\hline
\end{tabular}

$\overline{{ }^{62}}$ Cuando la sinalefa se da dentro del grupo de intensidad no la señalaremos por suponer este procedimiento evidente para el lector iniciado. Porque nos dirigimos a lectores avisados, tampoco hemos señalado las sinéresis o diéresis ni los casos de ley de equivalencia final, cuando se suma o resta una sílaba según la acentuación de la palabra al final del verso. Asumimos que estas consideraciones métricas 
Por último, en la tabla siguiente comparamos las cifras equivalentes al número de sílabas de los segmentos: en la primera columna según nuestra distribución semántica y en la segunda columna según la distribución dactílica:

\begin{tabular}{|lrrr|cccc|}
\hline \multicolumn{4}{|c|}{$\begin{array}{c}\text { Esquema de palabras } \\
\text { o grupos semánticos }\end{array}$} & \multicolumn{4}{c|}{ Esquema silabotónico de pies dactílicos } \\
\hline 2 & 2 & 3 & $4=11$ & 3 & 3 & 3 & $2=11$ \\
\hline 2 & 2 & 3 & $4=11$ & 3 & 3 & 3 & $2=11$ \\
\hline 2 & 2 & 4 & $3=11$ & 3 & 3 & 3 & $2=11$ \\
\hline 3 & -5 & 4 & $=11$ & 3 & i3? & 3 & $2=11$ \\
\hline 3 & 5 & 3 & $=11$ & 3 & i3 & 3 & $2=11$ \\
\hline 3 & -2 & 4 & $3=11$ & 3 & 3 & 3 & $2=11$ \\
\hline
\end{tabular}

Antes de mostrar las diferencias de los dos sistemas, observemos primero las semejanzas. Ambos esquemas están construidos sobre una frecuencia rítmica de cuatro o tres segmentos o grupos. Esta coincidencia permitió aplicar la estructura de tres pies dáctilos y un troqueo a este tipo de endecasílabo, y toda la teoría que de ello derivó. Por su variabilidad y pocas posibilidades de sistematización, se desechó toda la probabilística que implicaban las estructuras naturales del lenguaje. Los pies servían más a la construcción de la sistematicidad de un sistema teórico que los «caprichos» semánticos y sintácticos aleatorios del lenguaje con sus incontables combinaciones. Pero

bastante conocidas se infieren. Ahora bien, nos ha parecido importante señalar con un guion la sinalefa que se da entre dos palabras o grupos de intensidad (vv. 4, 6). Consideramos que ocurre una superposición de los dos fenómenos, demarcación de la palabra o grupo de intensidad por el acento y debilitamiento de los límites debido a la sinalefa. Este «conflicto» no impide que separemos los dos grupos semánticos. Entre el acento como elemento demarcativo y la sinalefa como elemento que debilidad tal demarcación, creemos que tiene mayor peso el acento. En este sentido, Bělič precisa: «si bien el acento español no señala claramente el límite entre las palabras/los grupos de intensidad (borrado, además, en muchos casos, por la sinalefa y el enlace), señala como cima prosódica, de un modo inequívoco, la presencia de estos grupos (de cada uno de ellos). Si no tiene (suficiente) valor demarcativo, tiene, como hemos dicho, claro valor individualizador. En el verso español hay tantos grupos de intensidad -que son unidades semánticas- cuantos acentos léxicos hay.» (BĚLIČ, Oldřich: Verso español y verso europeo, cit., pp. 137-138.) 
una irregularidad regulada no es óbice para implementar un sistema. Se puede establecer una regularidad irregular con esas combinaciones normales del español que se dan en torno a un acento. La regularidad se da, como indica Bělič, en determinado número de sílabas y en la cláusula final obligatoria. La irregularidad o variabilidad, como observamos en la columna de la izquierda, se da en los grupos o segmentos que dinámicamente se constituyen en torno a un acento.

Como vemos, en el esquema silabotónico dactílico (columna de la derecha) la regularidad predomina -gana el silabotonismo-, a pesar de la incoherencia silabotónica en los versos 4 y 5 , en los que falta un pie dactílico y la secuencia se rompe. Como sabemos, tales versos no son incorrectos. Lo incorrecto es el sistema métrico que se les aplica. Como decíamos más arriba, este esquema abstracto nada tiene que ver con la realidad del lenguaje, incluso en casos extremos, intencionalmente dactílicos, como Iconos.

En el esquema semántico la situación es otra. Ahora la variabilidad predomina - gana el verso variable- y es altamente probable que, debido a su semantismo, los segmentos - palabras o grupos de intensidad-si sean naturalmente percibidos por el lector que generalmente desconoce las cuestiones métricas. No son los pies los que provocan el ritmo mayoritariamente de cuatro que observábamos en ambos esquemas. Son las agrupaciones lógicas, normales, del lenguaje las que, en grupos de cuatro o tres segmentos que se alternan, crean una serie que, siendo regular por esta misma frecuencia, es irregular por la variación de sus grupos.

Por si quedan dudas, vamos a observar ahora si tal variabilidad ocurre también en el último fragmento de Iconos, cuya regularidad dactílica era completa:

\begin{tabular}{|c|c|c|}
\hline Versos & $\begin{array}{l}\text { Acentos } \\
\text { silabotónicos }\end{array}$ & $\begin{array}{c}\text { Palabras } \\
\text { o grupos } \\
\text { semánticos }\end{array}$ \\
\hline [Ámbitos!][ Áncha][ demóra][ de tí!] & 14710 & 32333 \\
\hline [Pádre], [otórgame] [el nómbre] [que llévo ] & 14710 & $24-23$ \\
\hline [Más!][ Demandándo] [en mi muérte,][ la Vida!] & 14710 & $14-33$ \\
\hline [Hé] [concluido] [el mirár!] [Y retórno!] & 14710 & $14-24$ \\
\hline
\end{tabular}




\begin{tabular}{|c|c|c|}
\hline$[$ Ícono $][$ póstumo, $][$ cárta $][$ selláda?] & 14710 & 33223 \\
\hline [Nómbrame $][$ yá,] [victorióso] [de Amór...] & 14710 & 3143 \\
\hline
\end{tabular}

Como constatamos, pasamos de una regularidad silabotónica dominante (primera columna), aunque arbitraria e irreal, a una irregularidad semántica real (segunda columna), que se ajusta al lenguaje. No obstante, admitimos que ambos sistemas pueden convivir, pero creemos que el concepto de verso variable integra mejor las particulares acentuales del conjunto de los versos. La presencia del verso variable, a nuestro modo de ver, es más conveniente al principio de reunión de contrarios de la poesía de Almanza.

A manera de conclusión, podemos decir que Iconos es un nuevo caso de uso intencional del moderno endecasílabo dactílico, que el uso y la extensión de tal variante del endecasílabo son necesarios a sus fines estéticos -entre otros, la reunión dentro del paradigma métrico verso variable- y que, finalmente, sitúa la barra de la ejecución de este metro mucho más alta que la de sus predecesores.

\section{Bibliografía utilizada}

ALMANZA ALONSO, Rafael: Libro de Jóveno. Miami: Ediciones Homagno, 2003.

—:El gran camino de la vida. Miami: Ediciones Homagno, 2005.

—:HymNos. Miami. Ediciones Homagno, 2014.

ARCOS, Jorge Luis: «Las palabras son islas. Introducción a la poesía cubana del siglo XX», en Las palabras son islas. Panorama de la poesía cubana Siglo XX (1900-1998). La Habana: Letras Cubanas, 1999.

BAEHR, Rudolf: Manual de versificación española. Madrid: Gredos, 1989. $4^{\text {a }}$ reimpresión.

BARQUET, Jesús: «Nueve criterios para armar y una conclusión esperanzada», en Jesús Barquet y Norberto Codina (eds.): Poesía cubana del siglo $X X$. México: FCE, 2002.

BĚLIC, Oldřich: Verso español y verso europeo, Introducción a la teoría del verso español en el contexto europeo. Santafé de Bogotá: Instituto Caro y Cuervo, 2000.

CABEZAS MIRANDA, Jorge: Proyectos poéticos en Cuba (1959-2000). Alicante: Universidad de Alicante, 2012. 
DOMÍNGUEZ CAPARRÓS, José: Métrica española. Madrid: Síntesis, 2000. —:Diccionario de métrica española. Madrid: Alianza Editorial. 2007. $2^{\mathrm{a}}$ reimpresión.

—:El moderno endecasílabo dactílico, anapéstico o de gaita gallega. Sevilla: Rhythmica, Revista española de Métrica Comparada. Anejo III, 2009.

—:«El endecasílabo dactílico en poesía popular», Rhythmica, 2009, VII, 7, pp. 227-237.

DORTA, Walfrido: «Estaciones, estados, documentos: panorama de la poesía cubana en los ' 80 y los '90 del siglo XX», Anales de literatura Hispanoamericana, 2002, vol. 31, pp. 17-38.

FERGUSON, William: La versificación imitativa en Fernando de Herrera. Londres: Tamesis, 1980.

HENRÍQUEZ UREÑA, Pedro: Obras completas. Estudios Métricos. Tomo III. Santo Domingo: Secretaría de Estado de Cultura, Editora Nacional, 2003.

LÓPEZ LEMUS, Virgilio: El siglo entero. El discurso poético de la nación cubana en el siglo Xx. 1898-2000. Santiago de Cuba: Editorial Oriente, 2008.

—: «La literatura cubana entre 1989 y 1999. Panorama de la poesía», en Portuondo, José Antonio (Dr.), Cira Romero y Sergio Chaple (coords.): Historia de la literatura cubana. Tomo III. La revolución (1959-1988). La Habana: Instituto de literatura y lingüística «José Antonio Portuondo Valdor», Ministerio de Ciencia, Tecnología y Medio Ambiente, Letras Cubanas, 2008.

NAVARRO TOMÁS, Tomás: Métrica española. Reseña histórica y descriptiva. La Habana: Edición Revolucionaria, Instituto del Libro, 1968.

PARAÍSO, Isabel: La métrica española en su contexto románico. Madrid: Arco/Libros, 2000.

PARDO, Arcadio: «El endecasílabo con acentos en 6a y 7a sílabas», en $\mathrm{Va}$ riations autour de la poésie. Hommage à Bernard Sesé. Nanterre: Publications du C.R.I.I.A, Université de Paris X, 2001.

—:«Verso aislado, verso solo, verso-poema». Rhythmica, 2004, II, 2, pp. 201-233.

QUILIS, Antonio: Métrica española. Barcelona: Ariel, 2013.

VALERA MERINO, Elena, Pablo Moíno Sánchez y Pablo Jauralde Pou: Manual de Métrica española. Madrid: Editorial Castalia, 2005. 